\title{
ANALYSIS OF CONSTRUCTION TECHNOLOGY IN SASH WINDOWS IN PERSIAN ARCHITECTURE (OROSI)
}

\author{
NIMA VALIBEIG \& ANAHITA RANJBAR* \\ Art University of Isfahan, Shahid Beheshti University, Iran
}

\begin{abstract}
Designing window openings (in buildings) has always been challenging for architects. Meticulous techniques have been used for constructing Sash windows in the past. Analysis and assessing these methods can provide better cognition of these windows. As a result, new solutions are provided for contemporary architecture. Investigations on Sash windows only have been dealt with aesthetic and climate aspects, and the construction techniques and their details have never been investigated. This research has studied and classified different types of this particular window by introducing the structural features, for the very first time. The data in this article have been gathered by library studies and field observations of case studies in Iran. In this research, different types of Sash windows are introduced and classified; moreover, construction techniques of each type by providing details are presented. By analysing these windows, their importance will be revealed in the past. Furthermore, by analysing the applied details, new solutions could be obtained for further designs.

Keywords: sash window (Orosi), wooden window, construction techniques, performance details.
\end{abstract}

\section{INTRODUCTION}

From old ages, the human has always been trying to create valuable artworks to provide comfort and tranquillity in life. Sash window (Orosi) is a latticed window which opens upward and positioned in a particular place at the top, instead of revolving around a hinge [1]. Lattice doors and windows with coloured glasses are great shades in Iran's harsh sunlight; moreover, they reflect the light in different colours. This variety of colours provides a great sight for the building.

The techniques of constructing these windows are fading away; thus, revitalizing this precious art is indispensable today. Because of harsh sunlight in Iran's climate, especially in warm seasons, large openings are not possible in building facades. Although Sash windows provide the space with sufficient light, they protect the inner space from the harsh sunlight. This particular facility makes the cognition and analysis of construction techniques essential.

Questions:

1. What was the application of Sash windows in traditional buildings?

2. What are the types of Sash windows and what features does each type have?

3. What are the details of Sash windows and how do they join to each other?

This research has classified and evaluated all types of Sash windows by analysing them. Furthermore, it has introduced different details and their function using field observations, library studies and 2D and 3D software packages.

\section{LITERATURE REVIEW}

If daylight is considered to be essential for the use to which room will be put, then windows are an unavoidable necessity [2]. Sash windows (Orosi) are constructed in odd window

*ORCID: http://orcid.org/0000-0001-5540-4625 
leaves, so that if it is used on the first floor, it covers the main part of the whole wall of the room (usually Shahneshin hall - the main space in traditional houses in Iran which is the largest space that has the most decorations (alcove) hall) and if it is built in upper floors (on the Gooshvar room - small rooms located in the corners of the first floor (above ground floor) in traditional houses in Iran), it is at most with three window leaves due to the low width. Protection measures must prevent glare and regulate the inflow of heat from sunlight [2]. Sash windows were usually covered with coloured glasses. Also, sash windows built at homes are always being opened to a yard (central courtyard-side yards) and never directly to the street [3]. Coloured glasses let the person inside the room view outside. But individuals who were outside, could not see the inside. In addition, they protected from direct sunlight and unpleasant warming in summer during the warm seasons [4]. That's the reason why some researchers count Sash windows as a passive cooling system [5].

Sash windows were used in different places such as houses, mosques, schools, Sarās (historical malls in Iran), and holy shrines, for this, their forms and numbers were different based on the places they were applied. Although, the sash in the first stage, is considered as an architectural element, in second step it is a part of the impressive architectural ornament. This has led to contemplate its decorative role more than its architectural character [6]. Based on the studies conducted, motives and decorations of the sash windows in different climates have many similarities. Moreover, the use of colours in the glass include complementary colours such as red-green, blue-yellow and orange-purple [3].

\subsection{The structure and form of the doors and windows}

Wooden doors and windows, whether they were decorated by latticework or by base frameworks using the tools, have a main skeleton that is attached to the piers and spans in pre-designed and well-proportioned places with different forms and dimensions. These areas are anticipated in the building, so that extra load is not imposed on the doors and windows except their weight, and are connected to the structure by different ways that resist against the various forces including the wind [7]. Traditional architects were using geometry for shaping the form of buildings so as to control their aesthetical and statistical features [8]. According to the statements of writers, it could be concluded that Orosi (sash window) is an extensive window including two upper and lower fractions that the upper one includes Pataq or Katibeh (inscription) and lower one usually includes leaves (small doors) [9]. Sash windows have different designs depending on their type: Three leaves, five leaves, and seven leaves. A combination of geometric and floral patterns was used in a significant number of sash windows that covers the entire upper surface of the window [10].

\section{METHODOLOGY}

There are similarities and differences among sash windows and other windows regarding their construction technology. Field studies, including surveying, imaging, and modelling were conducted to attain this knowledge. For obtaining the data validity, all models were assessed by the master workers in several stages, and for obtaining the data reliability, these experts were selected from different cities and age groups that are familiar with construction technology of this kind of window. In this regard, little changes are observed in experts' opinions, but generalities were the same. According to research method, main and sub components of the sash windows have been illustrated in the reconstruction. 


\section{TYPES OF OPENINGS FOR MONUMENTS}

\subsection{Pop-ups}

There are two kinds of pop-ups: transitional and rotational. Transitional pop-ups move horizontally or vertically, and rotational pop-ups rotate upon a hinge. If this hinge is placed in the centre, it is called centre-oriented, and if it is put in a corner, it is called corner-oriented (Fig. 1).

\subsection{Classification of sash windows}

\subsubsection{Geometry}

Sash windows have different geometrical variety in their façade. The number of odd leaves $(3,5,7,9)$ and different geometrical forms and decorations of the leaves are the outstanding features of these windows. Therefore, these windows have become one of the most decorative elements in traditional buildings. In general view of these windows, different geometrical forms were used so that sash windows can be built in a variety of places with different performances (Table 1).

\subsubsection{Plan}

Since the sash windows have no variety regarding the plan and are similar; therefore, two kinds of general plans of sash windows are shown (Fig. 2).

\subsection{Investigating construction details of Sash windows}

In all types of sash windows, there are same components as the main elements (Fig. 3); these components include vertical elements (columns) and horizontal elements (Kamaris (horizontal timber beam in sash windows)), connected to each other by special connections with no use of nails or metal fasteners (Fig. 4). Sash structural system is defined in the form of (mortise and groove joint) and (mortise and tenon joint). When the two sides of the hole in the wood are blinded, it is called tenon and when it is open, is called groove (Fig. 5).

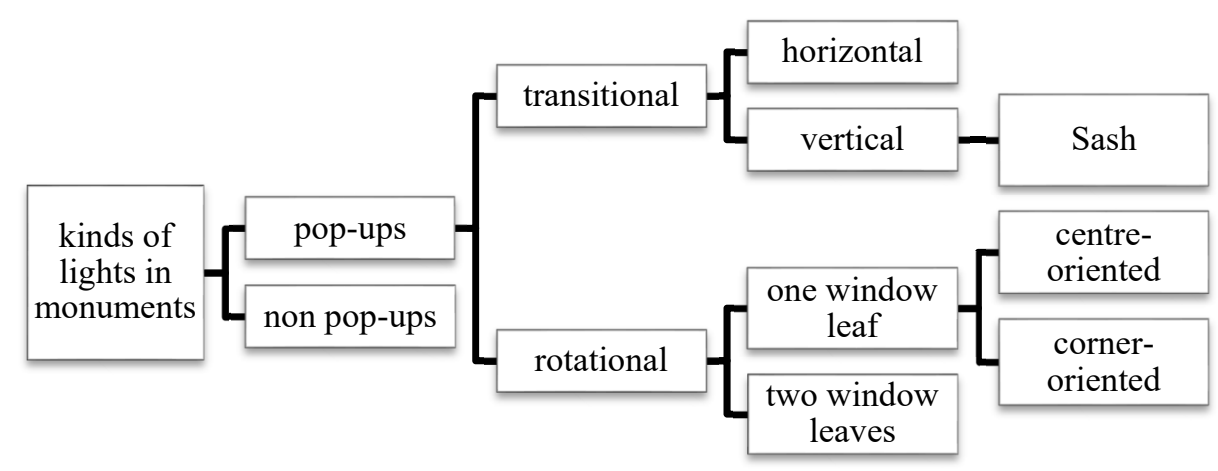

Figure 1: Classification of different kinds of openings in monuments. (Source: authors.) 
Table 1: Categorizing sash windows according to the plan.

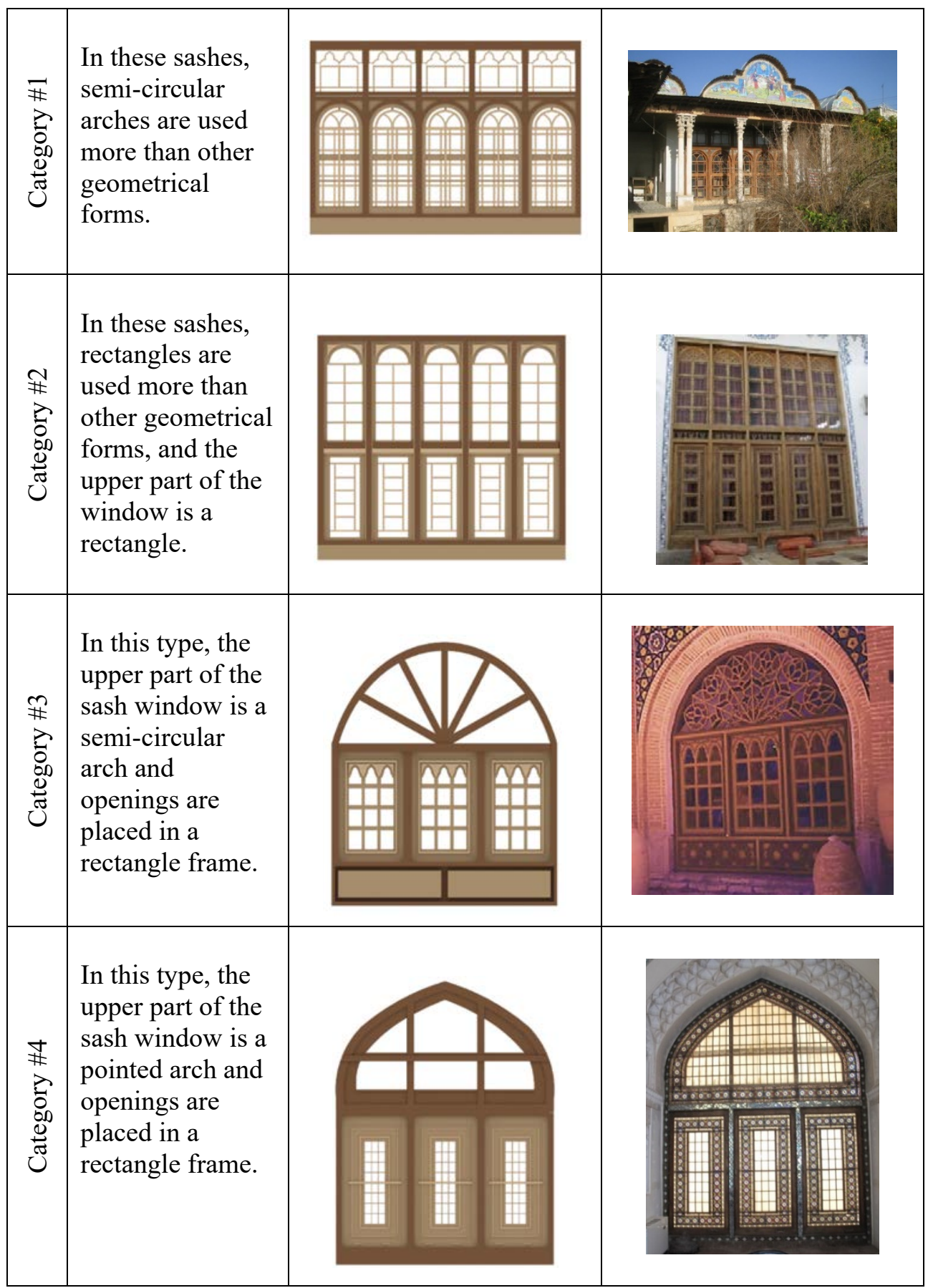




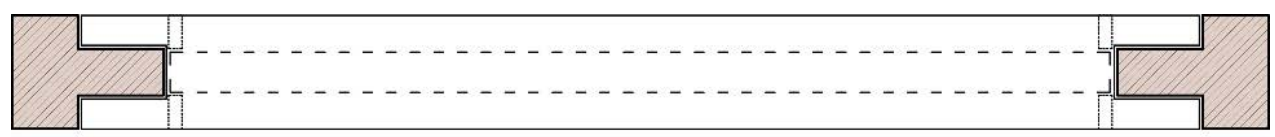

(a)

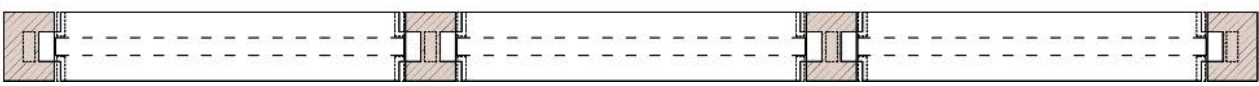

(b)

Figure 2: Types of Sash windows in the plan. (a) Plan with two grooves and two mortises; (b) Plan with one tenon and one mortise. (Source: authors.)

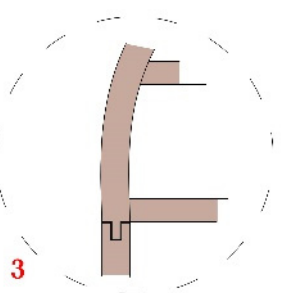

1

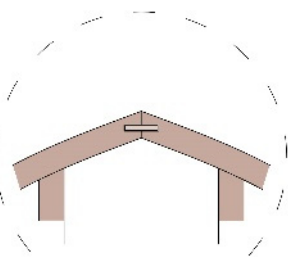

4

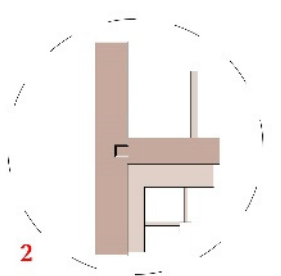

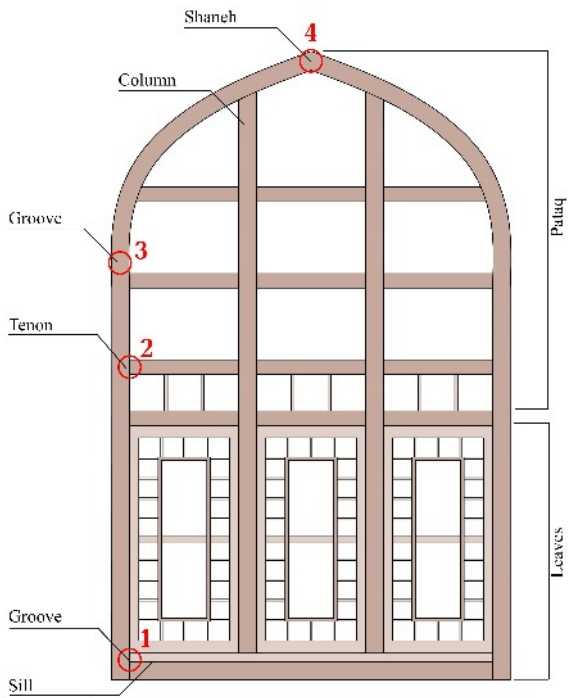

Figure 3: Components of a sash window.

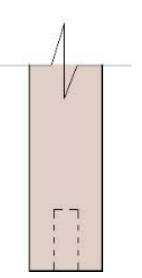

(a)

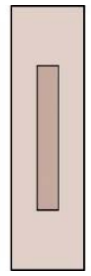

(b)

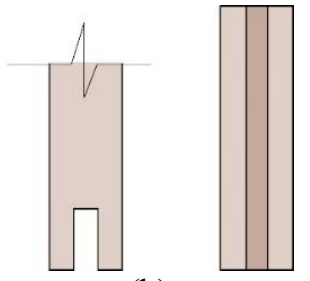

Figure 4: (a) Mortise and groove joint; (b) Mortise and tenon joint. 


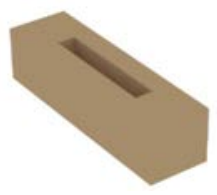

(a)

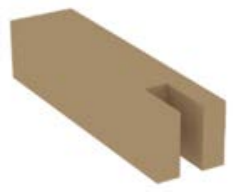

(b)

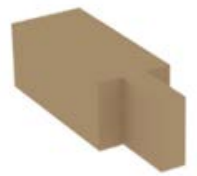

(c)

Figure 5: (a) Tenon; (b) Groove; (c) Mortise.

The place where the wooden beam is inserted into other timber is called tenon and when the wood is inserted vertically into other wood is called groove, and this is the same for all parts of sash window using this system.

\subsection{The mortise and tenon joint}

Traditional architects were considered mortise narrower than the tenon opening for implementing and constructing the sash windows and were used two wedges on both sides of the mortise, so that triangular wedges were fixed in the opening beside the mortise using the hammer (Fig. 6).

\subsection{Connections in different elements}

In the middle part of the columns, tenon and two mortises joint are used, and at the bottom, one mortise joint is used.

In the point of the arch of the sash windows with a pointed arch, the lateral connection of the two parts of the arch is conducted by two-sided mortises called "Shaneh" (two-sided mortise, located between lateral parts of the arch) (Fig. 7).

The way sash windows are built, and the order of column placement and horizontal wood (Kamari) is dependent on the adjusting and the method of construction.

If the height of the Sash window is high, for preventing the vibration, the column is built from bottom to the top and Kamaris are inserted into the column and set up the main column as the tenon. In other situations, columns are placed on the bottom and one horizontal kamari would place on them, and other parts of the columns will adjust above the Kamari. In these situations, columns are connected by inserting mortise inside the kamari (mortises are longer in this case). In general, integrated wood pieces form the tenon, and fragmented pieces of wood create the mortise (Fig. 8).
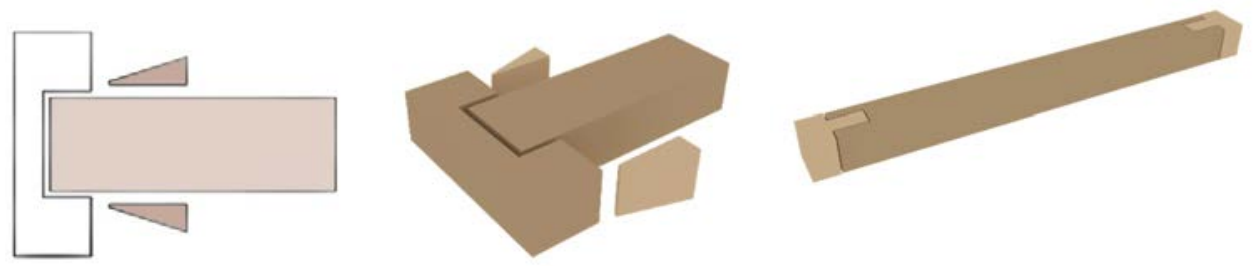

Figure 6: Tenon and mortise joint. 


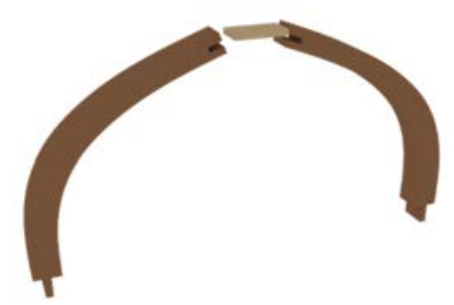

Figure 7: The lateral connection of the two parts of the arch with Shaneh.

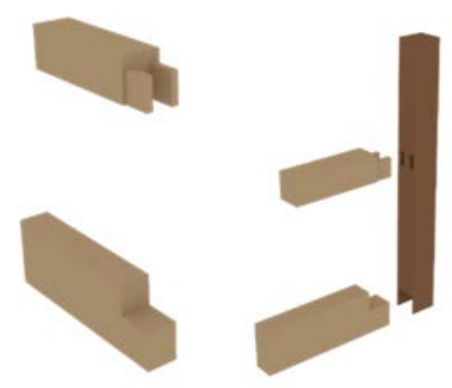

Figure 8: Middle and bottom column joints.

In short, all connections of wooden beams in the Sash windows are in the form of tenon and mortise without using of metal fasteners. These simple joints, have high durability and are more consistent with the nature of wood than other types of metal fasteners (Fig. 9). Unfortunately, using these valuable techniques in contemporary architecture is forgotten, and wooden structures are built with no consideration of the materials. Also, metal connections would result in wood damage and reduce its durability.
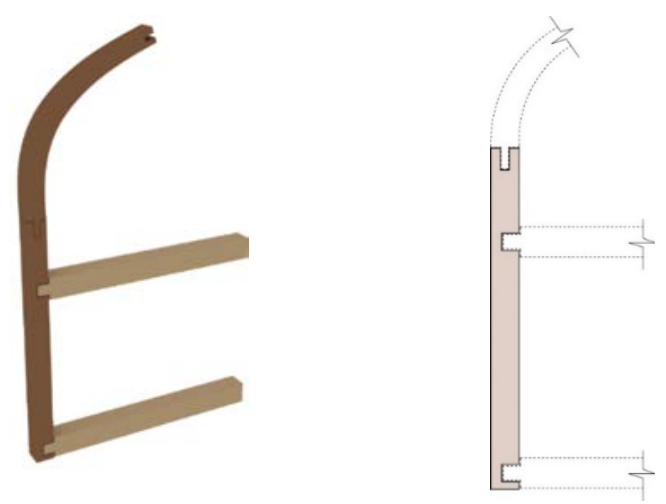

Figure 9: Details for connecting the kamaris to the columns. 


\section{CONCLUSIONS, DISCUSSION, AND RECOMMENDATIONS}

Sash windows provide the maximum light during the day due to the wide range of the view. Moreover, they prevent the redundant sunlight enters the building regarding the divisions, decorative wooden patterns and colour glasses.

Geometrical variety and their form flexibility were provided for constructing this kind of window for various buildings and different places. In this research, the sash windows were categorized based on the shape and geometry of the main components of it.

Sash windows with their high diversity follow the same pattern in the structures. The main elements of the columns include kamari and mortise and tenon joints that have been designed and implemented on the integration of the wood. One of the impressive features in this joints is the lack of usage of nails and metal fasteners that may result in greater stability and strength of the elements.

This study for the first time has introduced and categorized a variety of sash windows, and also by providing the structural details, explained this beautiful and valuable window, while in the other studies, only functional and architectural aspects of these windows in the monuments were discussed. Following and using the prior knowledge and combining it with the modern architecture is needed to achieve the new designs in contemporary buildings that can be considered in future studies.

\section{REFERENCES}

[1] Pirnia, M.K., Introduction to Islamic Architecture, ed. G.H. Memarian, Soroush Danesh Institute: Tehran, 2011.

[2] Neufert, E., Neufert, P., Baiche, B. \& Walliman, N., Architect's Data, Blackwell Science: Oxford, 2011.

[3] Bozorgmehri, Z., Iranian Ornaments, Soroush Danesh: Tehran.

[4] Fathi, H. \& Rohanian, S.H., Comparative semantics of wooden sash windows and lead sash window (Rose window). Indian Journal of Fundamental and Applied Life Sciences ISSN, 5(S1), pp. 1284-1290, 2015.

[5] Khashei, Z., The role of passive systems in providing comfort in traditional houses in Isfahan: A case study of the Karimi house. Eco-Architecture III Harmonisation Between Architecture and Nature, pp. 271-280, 2010.

[6] Zarei, M.I., Sanandaj, city of sash windows, study of the formation and expansion of the building sash window art based on the existing examples. Iranian Architecture Studies, pp. 109-130, 2013.

[7] Iravani, H., Bozorgian, A.H., Laricheh, D., Karimi, S., Sadat Safavi, Z. \& Semsar, I., Analysis and comparison of plans and designs of the Iranian Sashes (a case study of Angurestan Malek in Isfahan - mansion house windward in Tehran - Arg Karim Khan in Shiraz - Dolat Abad Garden in Yazd - building Salar Said in Sanandaj). Buletin Teknol Tanaman, pp. 42-47, 2015.

[8] Vafi, M.H., Window on the residential architecture of the Safavid period. Art 52, pp. 119-143, 2002.

[9] Mehdizadeh, F., Tehrani, F. \& Valibeig, N., Applying the 'Hanjar' triangles in the mathematical calculation, implementation and enforcement of traditional Iranian architecture. Restoration and Architecture of Iran, pp. 15-26, 2011.

[10] Amraei, M., Sash Windows Toward the Light, Lily Publishing Company: Tehran, 2004. 